\title{
Research on International Capacity Cooperation in Yunnan Province against the Background of "the Belt and Road"
}

\author{
Shen Shen $*$ \\ Economic Department of Teaching and Research \\ Party School of the Yunnan Provincial Committee of C.P.C \\ \&School of Economics \\ Yunnan University of Finance and Economics \\ Kunming, China \\ leon198633@sina.com \\ *Corresponding author
}

\author{
Yan Hui \\ School of Economics \\ Yunnan University of Finance and Economics \\ Kunming, China \\ yanhui4779@163.com
}

\begin{abstract}
Against the background of "the Belt and Road", Yunnan province is the hub of two economic corridors, namely China-Indochina Peninsula Economic Corridor and BangladeshChina-Burmese Economic Corridor. Moreover, Yunnan province is also the core of "herringbone" Sino-Myanmar Economic Corridor. Based on the provincial condition of Yunnan and existing relevant research, this paper discusses problems in the international capacity cooperation. Applying game analysis methods, it also studies behavioral decision makings of all stakeholders. At last, it puts forward targeted policies and suggestions which aim to promote international capacity cooperation and achieve mutual benefit and win-win results between Yunnan province and its neighboring countries.
\end{abstract}

Keywords- "the Belt and Road"; International Capacity Cooperation; Yunnan province

\section{INTRODUCTION}

According to the 19th National Congress of the Communist Party of China report, we should take "the Belt and Road" as a priority, give equal emphasis to "bringing in" and "going global", follow the principle of achieving shared growth through discussion and collaboration, and increase openness and cooperation in building innovation capacity. With these efforts, we hope to make new ground in opening China further through links running eastward and westward, across land over sea. In the new era, the "Belt and Road Initiative" emphasizes that China should create a community of economic interests, a community of social responsibility and a community of ecological environment with the countries along the border line, therefore finally creating a community of share future for mankind, in which weal and woe are equally shared and sustainable de velopment could be achieved (Liu Wei, Wang Wen, 2017). [4] In addition, Yunnan province is the hub of two economic corridors, China-Indochina Peninsula Economic Corridor and Bangladesh-China-Burmese Economic Corridor. At the same time, it is also a key node in the Greater Mekong Sub-region. After since the Ministry of Foreign Affairs proposed the establishment of "herringbone"

This paper is funded by "Research on Industrial Transformation and Upgrading of Yunnan Province under the Concept of Green Development" (2018XT015), “Research on Farmers' Producing Behaviors under the Regulation of Yunnan Tobacco" (2017FD125), "Research on Circulation Competitiveness of Yunnan Tobacco Enterprise” (2016D01).
Sino-Myanmar Economic Corridor, China and Myanmar have been jointly exploring the construction of the certain corridor which starts from Yunnan province of China in the north, goes south to Mandalay along the Sino-Burmese border, and then extends eastward and westward respectively to Yangon New Town and Kyaukpyu Special Economic Zone. Through the construction of the "herringbone" China-Myanmar Economic Corridor, a big cooperation pattern, which with a situation of tripartite confrontation and three-end support, will be formed (Wang Yi, 2017). All these prove that Yunnan Province has an important strategic position and it can achieve mutual benefit and win-win results through the international capacity cooperation.

\section{LITERATURE REVIEW}

The core of international capacity cooperation is "cooperation". It not only refers to the output of industries and capabilities, but also emphasizes the export of the entire industry to different countries so as to help these countries to establish a more complete industry (An Yuhong, 2015). [5] International capacity cooperation is not only an important means of realizing industrial rejuvenation in the "the Belt and Road" (Liu Zongyi, 2015), but also a "double-edged sword" (Kurien, 2016). The capacity cooperation between China and the Middle East has advantages and potential disadvantages (Wei Min, 2016). In the pattern of behavioral, SinoKazakhstan capacity cooperation shows a trend of development from asymmetry to symmetry mutualism symbiosis (Zhang Hong, Liang Song, 2015). The key of international capacity cooperation between China and Turkey lies in enhancing political mutual trust and security cooperation (Wei Min, 2017). The Chinese strategies for international capacity cooperation can accelerate the promotion of status of Chinese global value chain and create new comparative advantages in the Belt and Road. It is also a realistic requirement for the adjustment of industrial structure and the optimization of key elements in China (Qiu Bin et al., 2016). It is necessary for government departments to play the role of matchmakers and the superior capacity should play the leading role actively ( $\mathrm{Li}$ Xuejie, Hu Gaofu, 2016). Moreover, it is also necessary to proceed with the concept of innovative 
cooperation. And a specialized agency for production cooperation should be established to accelerate the pace of going out of the upgraded version of "Made-in-China" (Jin Ruiting, 2016). Therefore, Yunnan province should seize the opportunity of development in the Belt and Road with focusing on building the green economy industrial clusters in the northwest and southwest and constructing the southeast highland eco-industrial chain comprehensively (Li Zhongbin et al., 2015).

To sum up, the current research on international capacity cooperation mainly starts with the national level and partially combines with the regional development. It is also focusing on the aspects of industrial development, international trade and so on. It aims at increasing the value chain, extending the industrial chain and building a community with symbiotic relationship and shared interests. However, there is a lack of analysis of the problems in the international capacity cooperation from the micro level, and especially the research that based on the actual situation in Yunnan province. Yunnan Province which is located in the southwest border of China borders on Myanmar, Laos, and Vietnam. It is a key node of two southwest corridors in the Belt and Road. Therefore, based on the analysis of problems existing in the international capacity cooperation in Yunnan Province and from the perspective of game theory, this paper discusses the behavioral decision makings of various stakeholders in an in-depth manner and strives to solve the problem of cooperation which is caused by information asymmetry and conflicts of national interests. So that in this case, it can make up for the insufficiency of the relevant research and ensure the realization of mutual benefit and win-win results. Therefore, this paper has important theoretical and practical significance

\section{PRoblems in InTERNATIONAL CAPACity COOPERATION OF YUNNAN PROVINCE}

Through the international capacity cooperation, Yunnan province and its neighboring countries have gradually formed friendly relationships cooperation with complementary advantages, mutual benefits and win-win results. At the national strategic level, Yunnan province has gradually opened up new trade routes. In particular, the United States has strengthened the blockade of the Straits of Malacca and restrictions on China, owing to the "reverse globalization" in the United States and the escalation of Sino-US trade frictions. The establishment of two economic corridors under the Belt and Road will ease the tense trade environment and enable Yunnan province to better play its role as a radiation center faced to South Asia and Southeast Asia. By strengthening the cooperation, Yunnan province and its neighboring countries will achieve mutual benefit and common development. However, Yunnan province still has many problems in the international capacity cooperation, which are mainly manifested in:

\section{A. Long-standing overcapacity and insufficient effects of mutual benefit}

The problem of overcapacity in Yunnan province is very serious, especially after undertaking industrial transfer. The traditional extensive development mode has made it stay in the low-end of the value chain for a long time. The sluggish domestic and overseas markets of primary industrial products have determined the long-term existence of overcapacity. Taking the cement industry as an example, except for Yunnan province, there is serious overcapacity in Guizhou province and Sichuan province in southwest China. However, they have not taken advantage of the opportunities of international capacity cooperation to export overcapacity to the neighboring countries effectively. Relatively speaking, most industries in Yunnan province have certain advantages and the neighboring countries of Yunnan province have abundant resources and adequate labor force. However, the mutual benefit effect of cooperation has been limited, owing to the insufficient crossborder cooperation and underutilized peripheral international markets.

\section{B. Insufficient utilization of comparative advantages and excessive restrictions on trade channels}

Yunnan Province has comparative advantages in traditional industries, such as the tobacco industry and plateau characteristic agriculture. The big health industry, represented by Yunnan Baiyao Group, is also highly competitive around the globe. Unfortunately, neither has this advantage fully played its role in the international capacity cooperation, nor has it led other industries. Instead of creating the "centralperiphery" model to lead motivate economic development by turning the "peripheral" countries into the supply areas of raw materials or labor force just like those multinational corporations; it pays more attention to commodity trade. In addition, due to restrictions on the import and export channel policy, the products of the neighboring countries which are badly in need of export, such as Burmese rice, are difficult to enter into China on a large scale. Since primary products like agricultural products are the priority of the neighboring countries, these restricts reduce the enthusiasm of cooperation to some extent.

\section{The poor communication of capacity cooperation and the incomplete mechanism of interest coordination}

The main point of the international capacity cooperation is to look for opportunities to achieve common development among the participants. The neighboring countries which border on Yunnan province mainly rely on the export of resources, while the main output of China is industrial which is represented by oil and gas pipelines, high-speed rails and power stations. However, in the international capacity cooperation, owing to misunderstanding in cultural difference and inaccurate distribution of interests, both sides lost opportunities and brought problems. For example, Japan has obtained the rehabilitation right of the Myanmar railway and the construction of China-Myanmar Myitsone Hydropower Station has been locked out. The latter is involved in environmental issues. These problems are resulted from a multi-player game. From this, we can see that the fundamental of international capacity cooperation is to find the common ground of interests so that the cooperation can go on smoothly. And in particular, enterprises in other countries must play an active role in promoting cooperation. 


\section{GAME ANALYSIS IN INTERNATIONAL CAPACITY COOPERATION}

Firstly, in the international capacity cooperation, the primary issue is the balance of national interests. If countries only consider the maximization of their own interests, due to the Long-standing information asymmetry and the lobbying of domestic enterprises, they will fall into "the prisoner's dilemma". Assuming the existence of government 1 and government 2, the policies of international capacity cooperation that can be adopted are opening-up and setting barriers to the outside world, while the latter mainly focuses on taxation. In addition, if the barriers are set in the form of taxation, they will be equivalent to being imposed on the other government by $\mathrm{T} 2$ and $\mathrm{T} 1$ respectively. When both of the two countries choose the policy of opening-up to the outside world, they can obtain high yields, $\mathrm{H} 1$ and $\mathrm{H} 2$, respectively. However, when both sides choose the policy of setting barriers, they can obtain low yields, L1 and L2, respectively. Then, the cooperation will no longer exist. Specifics are as follows:

\begin{tabular}{|c|c|c|c|}
\hline & & Govemment 2 & \\
\hline & & opering-up & setting barriers \\
\hline Govemment 1 & opening-up & $\left(\mathrm{H}_{1}, \mathrm{H}_{2}\right)$ & $\left(\mathrm{B}_{1}-\mathrm{T}_{2}, \mathrm{~B}_{2}+\mathrm{T}_{2}\right)$ \\
\hline & setting bariers & $\left(\mathrm{B}_{1}+\mathrm{T}_{1}, \mathrm{~B}_{2}-\mathrm{T}_{1}\right)$ & $\left(\mathrm{L}_{1}, \mathrm{~L}_{2}\right)$ \\
\hline
\end{tabular}

Fig. 1. The payoff matrix of games between national governments competitiveness

According to the above figure, we can see that, due to their tax revenues and the pressure of domestic companies, both of governments will choose the policy of setting barriers. Therefore, the equilibrium result is (setting barriers, setting barriers) which will ultimately lead international capacity cooperation fail to proceed smoothly. It should have achieved "win-win" results through opening and cooperation, but finally turned into "double-lost" trade wars. This is the biggest problem that the Belt and Road needs to solve. We must strengthen the coordination and communication, adhere to the principle of mutual benefit and "win-win" results and promote the construction of a community of shared future for mankind.

Secondly, driven by asymmetric information and the entrenched interest, enterprises in different countries will also fall into "the prisoner's dilemma". Generally, enterprises that participate in the international capacity cooperation have certain market power in the domestic market. When the expected revenue in the cooperation is uncertain, the entrenched interest of enterprises that participate in the international capacity cooperation may likely be divided. Similarly, assuming the existence of enterprise 1 and enterprise 2 in different countries and the strategies that can be adopted by enterprise 1 and enterprise 2 are cooperation and non-cooperation. When both of the two enterprises choose the strategy of cooperation, they can obtain high yields, H1 and $\mathrm{H} 2$, respectively. Moreover, if one of the two enterprises choose the strategy of cooperation, while the other one choose the strategy of non-cooperation, the entrenched interest of the enterprise that choose to cooperate will be divided. The entrenched interest which be divided are represented by M1 and M2 respectively. However, when both of the two enterprises choose the strategy of non-cooperation, they will obtain low yields, L1 and L2, respectively. Then, the cooperation will no longer exist. Specifics are as follows:

\begin{tabular}{c|c|c|c|}
\multicolumn{3}{c}{ Enterprise 2} \\
\cline { 2 - 4 } Enterprise 1 & cooperation & non-cooperation \\
\cline { 2 - 4 } & cooperation & $\left(\mathrm{H}_{1}, \mathrm{H}_{2}\right)$ & $\left(\mathrm{B}_{1}-1 / 2 \mathrm{M}_{1}, \mathrm{~B}_{2}+1 / 2 \mathrm{M}_{1}\right)$ \\
\cline { 2 - 4 } & non-cooperation & $\left(\mathrm{B}_{1}+1 / 2 \mathrm{M}_{2}, \mathrm{~B}_{2}-1 / 2 \mathrm{M}_{2}\right)$ & $\left(\mathrm{L}_{1}, \mathrm{~L}_{2}\right)$ \\
\cline { 2 - 4 } &
\end{tabular}

Fig. 2. The payoff matrix of games between enterpris es in different countries

Therefore, based on the maximization of their own interests, both of the two enterprises will choose the strategy of non-cooperation. And the equilibrium result will be (noncooperation, non-cooperation). If the distribution of interests between enterprises can not be coordinated or there is a lack of confidence in expected returns, the international capacity cooperation will still be difficult to shape even with the help of national government forces.

Lastly, even if foreign enterprises enter the domestic market through the international capacity cooperation, they will also face the competitive pressure from domestic enterprises. There is a dynamic game of incomplete information because the cost structure of domestic enterprises is unknown. First of all, transforming it into a game of complete but imperfect information through the Harsanyi transformation with giving domestic enterprises a high-cost probability and a low-cost probability by nature. And probabilities of each is $1 / 2$. When foreign enterprises enter the domestic market, they will face a threat which is from domestic enterprises. Generally, the threat is in the form of competitions by the means of the expansion of production. Specifics are as follows (B represents the shared revenue of enterprises in the local market, $\mathrm{P}$ represents the shared revenue of the local enterprises after expansion, assuming $\mathrm{P}=2 \mathrm{~B}$, and $\mathrm{B}>0, \mathrm{P}>0)$ :

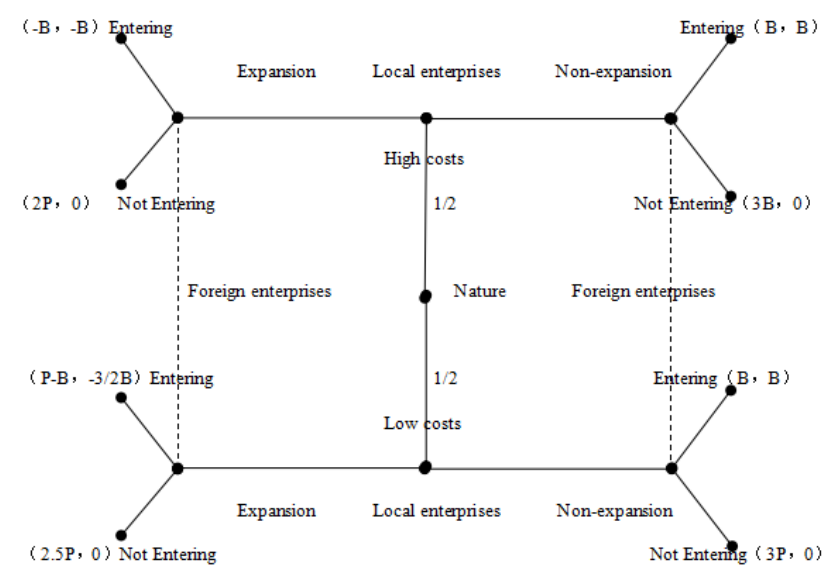

Fig. 3. Bayesian Revenue Matrix of Domestic and Foreign enterprises in the high-cost and low-cost conditions

From the above figure, we can see that the expected return of foreign enterprises entered the market is (entering: 1/2B$3 / 4 \mathrm{~B}=-1 / 4 \mathrm{~B}$; not entering: $1 / 2 * 0+1 / 2 * 0=0$ ), and Bayesian equilibrium is [not entering, (non-expansion, expansion)] which indicates that the threat of domestic enterprises is 
effective and foreign enterprises will not enter the local market. Therefore, based on the condition of incomplete information, foreign enterprises of the same type will be very difficult to enter the local market even with no barriers to entry, if the interests between domestic and foreign enterprises can not be coordinated.

\section{Conclusions and Policy Recommendations}

Against the background of "the Belt and Road", especially under the current circumstances that China is facing a slowdown in economic growth and has come to a critical point when it must speed up the transformation and upgrading of the industrial structure, international capacity cooperation is undoubtedly a new way to promote the complementarity of strengths in industrial structures among countries and optimize resources allocation in various countries. Based on special geographic advantages and provincial characteristics, this paper uses the game analysis method to study international capacity cooperation in Yunnan province against the background of "the Belt and Road". Due to the asymmetric information and the diversity of stakeholders, governments and enterprises will easily fall into "the prisoner's dilemma" when they seek international cooperation. Besides, foreign enterprises will also be threatened by domestic companies effectively when they enter the local market. Therefore, the policy recommendations are mainly as follows:

(1) The relevant policies should be formulated in accordance with the actual provincial conditions by the government of Yunnan province so that it can promote the formation of mechanisms of international capacity cooperation and accelerate the process of international capacity cooperation in Yunnan province. Since Prime Minister Li Keqiang proposed the plan of "China-Kazakhstan capacity cooperation" in 2014, "international capacity cooperation” is still a relatively new way of cooperation between countries. Countries are all exploring the process of promoting the international capacity cooperation at the same time. Owing to the relevant policy on international capacity cooperation in China has problems of decentralization and less pertinence, the government of Yunnan province should speed up the formulation of targeted policies and establish supporting systems and mechanisms.

(2) The government of Yunnan province should speed up the construction of regional infrastructure, including traffic infrastructure, between Yunnan province and its neighboring countries in order to promote the process of international capacity cooperation will be promote. For example, the ChinaThailand High Speed Rail, which started on December 21, 2017, will promote the development of the tourism industry and trade flows between Yunnan province and Thailand. However, it is necessary to prevent the other countries from controlling the right of railway construction at the same time; otherwise it may seriously affect the strategic cooperation among our country and the neighboring countries.
(3) Based on its own industrial structure and industrial layout, Yunnan province should actively cooperate with its neighboring countries (Myanmar, Laos, Vietnam and Thailand) to promote the complementarity of strengths and win-win cooperation. China has a historical relationship of trading and cooperation with countries in South and Southeast Asia, and the competitive edges of each country could be complementary and mutual beneficial. Furthermore, as the gateway of China to South Asia and Southeast Asia, Yunnan has a clear competitive edge in cooperating with countries in South and Southeast Asia.

(4) The government of Yunnan province should focus on the propaganda of its advantageous industries and famous brands, and explore overseas markets actively. Compared with the neighboring countries, Yunnan province has advantageous industries and a relatively complete industrial chain. Therefore, with the propaganda of advantageous industries and famous brands, the provincial government must seize the opportunity of international capacity cooperation to expand the share of overseas markets.

(5) The platform of international capacity cooperation should not only include state-owned enterprises, but also accept private enterprises that possess willing, capacity and complementary advantages. Therefore, on one hand, the cooperation would be more invigorated; on the other hand, countries could complement specific advantages with each other while more resources could be allocated better, thus leading to the transformation and upgrading of industrial structure.

\section{REFERENCES}

[1] Wu Fuxiang, Duan Yu, "International capacity cooperation and reshaping of Chinese economic geography,” Chinese Social Sciences, pp. 44-64+206, 2017(02).

[2] Xia Xianliang, "Building 'the Belt and Road' international capacity cooperation institutional mechanism and policy system," International Trade, pp. 26-33, 2015(11).

[3] Zhou Qin, Liu Xiuyan, Chen Jian, “An overview of the academic conference on 'International capacity cooperation under the background of the Belt and Road: theoretical innovation and policy research', Economic Research, pp. 188-192, 2016,51(05).

[4] Liu Wei, Wang Wen, "The construction of 'the Belt and Road' in the new era,” People's Forum, pp. 32-34, 2017(12).

[5] An Yuhong, “International capacity cooperation,” Macro Economic Management, pp. 83, 2015(10).

[6] Guo Jianxi, Yan Dong, "Risks and countermeasures of international capacity cooperation under the Belt and Road," International Trade, pp. 19-25, 2017(04)

[7] Qu Fengjie, "Breaking through the group-horse model and building a new geese group model-China's leading regional industrial division of labor system through international capacity cooperation,” International Trade, pp. 26-30, 2017(02). 